\title{
Predator control should not be a shot in the dark
}

\author{
Adrian Treves ${ }^{1 * \dagger}$, Miha Krofel ${ }^{2 \dagger}$, and Jeannine McManus ${ }^{3 \dagger}$
}

Livestock owners traditionally use various non-lethal and lethal methods to protect their domestic animals from wild predators. However, many of these methods are implemented without first considering experimental evidence of their effectiveness in mitigating predation-related threats or avoiding ecological degradation. To inform future policy and research on predators, we systematically evaluated evidence for interventions against carnivore (canid, felid, and ursid) predation on livestock in North American and European farms. We also reviewed a selection of tests from other continents to help assess the global generality of our findings. Twelve published tests - representing five non-lethal methods and 7 lethal methods - met the accepted standard of scientific inference (random assignment or quasi-experimental case-control) without bias in sampling, treatment, measurement, or reporting. Of those twelve, prevention of livestock predation was demonstrated in six tests (four non-lethal and two lethal), whereas counterintuitive increases in predation were shown in two tests (zero non-lethal and two lethal); the remaining four (one non-lethal and three lethal) showed no effect on predation. Only two non-lethal methods (one associated with livestockguarding dogs and the other with a visual deterrent termed "fladry") assigned treatments randomly, provided reliable inference, and demonstrated preventive effects. We recommend that policy makers suspend predator control efforts that lack evidence for functional effectiveness and that scientists focus on stringent standards of evidence in tests of predator control.

Front Ecol Environ 2016; 14(7): 380-388, doi:10.1002/fee.1312

Qubstantial numbers of vertebrate predators have been $\checkmark$ intentionally killed by government agencies and by private citizens acting legally or illegally (Wirsing and

\section{In a nutshell:}

- Predator control methods to prevent livestock loss have rarely been subject to rigorous tests using the "gold standard" for scientific inference (random assignment to control and treatment groups with experimental designs that avoid biases in sampling, treatment, measurement, or reporting)

- Across the controlled experiments that we systematically examined, higher standards of evidence were generally applied in tests of non-lethal methods than in tests of lethal methods for predator control

- Non-lethal methods were more effective than lethal methods in preventing carnivore predation on livestock generally; at least two lethal methods (government culling or regulated public hunting) were followed by increases in predation on livestock; zero tests of non-lethal methods had counterproductive effects

- All flawed tests came from North America; 10 of 12 flawed tests were published in three journals, compared to four of 12 tests with strong inference in those same journals

- We recommend suspending lethal predator control methods that do not currently have rigorous evidence for functional effectiveness in preventing livestock loss until gold-standard tests are completed

${ }^{1}$ Nelson Institute for Environmental Studies, University of Wisconsin, Madison, WI *(atreves@wisc.edu); ${ }^{2}$ Biotechnical Faculty, Department of Forestry, University of Ljubljana, Ljubljana, Slovenia; continued on p 388
Ripple 2010; Ripple et al. 2014). More recently, however, killing top predators - such as wolves (Canis lupus) and leopards (Panthera pardus), which occasionally prey on livestock - has prompted concerns associated with ethical issues (Vucetich and Nelson 2014), effectiveness, and ecological impacts. Depletion of apex consumers, which include most large-bodied predators, has led to the degradation of ecosystems and disruption of vital ecological processes worldwide (Estes et al. 2011; Ripple et al. 2014). As a result, traditional non-lethal methods have been reinstated and new approaches are being developed (Treves et al. 2009).

Questions about functional effectiveness center on whether intervening will protect property owners from future losses ("effectiveness" hereafter). The question remains unresolved for many cases but is particularly unclear for killing predators (Mitchell et al. 2004; Treves and Naughton-Treves 2005; Woodroffe and Redpath 2015). Although it seems obvious that killing a carnivore about to take a lamb should ensure the latter's short-term survival, most lethal methods are applied indirectly in wholly different situations. Lethal intervention is usually implemented after carnivores are observed near livestock or days after a predation event has occurred, sometimes far from where the attack occurred (eg Treves et al. 2002). Historically, eradication campaigns have been aimed at reducing predation by exterminating species. However, national and global concerns about biodiversity loss have largely discouraged this, when applied to native predators (Treves and 
Karanth 2003; Chapron et al. 2014). Furthermore, over time, numerous observers have noted that killing predators could fragment predator social groups or create vacancies in the ecological community, to be filled by more numerous, smaller species of predators that in turn might prey on livestock (Young and Dobyas 1945; Newby and Brown 1958; Haber 1996; Knowlton et al. 1999; Prugh et al. 2009). Indiscriminate killing was also often ineffective in removing probable culprits (Knowlton et al. 1999). Finally, for both lethal and nonlethal interventions, little information was available about the behavioral and population dynamic responses of survivors or any ripple effects, whereby neighboring livestock owners suffer higher costs after predator control was implemented on a nearby property. For example, in response to moderate rates of human-induced mortality, coyotes (Canis latrans) frequently showed compensatory reproduction, resulting in higher population growth rates and population densities during subsequent years (Knowlton et al. 1999). Controversy and uncertainty about predator control generally persisted for decades in the absence of convincing evidence. Resolving this controversy will help to restore populations of predators and other species in largely undisturbed ecosystems as well as in more developed landscapes with people and domestic animals (Fischer et al. 2008).

Prior studies of predator control reviewed evidence for one carnivore species (eg coyotes; Mitchell et al. 2004) or a single type of control method (Linnell et al. 1997; Mason et al. 2001), but general conclusions were elusive because standards of evidence varied or unreliable inferences arose from uncontrolled tests. As the field matured, so did its standards of evidence. Experiments with Australian sheep (Ovis aries), for instance, suggested that intense and frequently repeated killing of introduced red foxes (Vulpes vulpes) and dingoes (Canis lupus dingo) produced only minimal, inconsistent protection for lambs (Greentree et al. 2000; Allen and Sparkes 2001). Controlled experiments on three management techniques for European badger (Meles meles) - a mustelid - showed that lethal interventions significantly exacerbated disease transmission from badgers to livestock (Vial and Donnelly 2012). Nevertheless, predator control methods have not been subject to comprehensive "clinical trials", in which interventions that appear effective in "laboratory trials" are tested experimentally on real subjects, to borrow terminology and lessons from the biomedical sciences (Mukherjee 2010). Here we apply uniform criteria and an established standard of evidence to evaluate the effectiveness of various interventions used to prevent predation on livestock by carnivores (ie terrestrial members of Carnivora $>5 \mathrm{~kg}$, such as coyotes, wolves, bears, or big cats). We adopted the scientific framework for strong inference first articulated by Platt (1964) to review both the experimental design and the evidence for effectiveness of various, widely used lethal and non-lethal methods.
Strong inference demands the careful avoidance of bias at several stages, primarily through the use of an experimental control with random assignment of treatments, followed by unbiased measurement and reporting subjected to rigorous, anonymous peer review, with disclosure of potential conflicts of interest. For ease of discussion, we refer to random assignment of treatments as the "gold standard" for scientific inference but we also examine whether study designs included other steps to avoid bias in sampling, measurement, or reporting. We use the scientific terms "bias" and "flawed design" without any suggestion of intentional bias or incompetence. Often well-intentioned and highly competent researchers encounter flaws in research design because of inescapable challenges presented by field conditions. Nevertheless, the gold standard of scientific inference has been embraced by practitioners within the clinical biomedical sciences because of a long history of unreliable inferences from tests that had one or more biases in the sampling of subjects, treatments, measurements, or reporting (Mukherjee 2010). Unlike scholars in the paleosciences (Gould 1980; Biondi 2014) who have made cogent arguments for a lesser standard because studies of the past can never be replicated exactly to the specifications required by scientific experimentation, ecologists have long advocated for controlled experiments in ecological research (Hairston 1989). We therefore hold our subdiscipline to the gold standard. However, the shortage of tests meeting the gold standard (see below) led us to examine an alternative "silver standard" of non-random assignment of treatments, as long as we discerned - from a close reading of the peer-reviewed, published methods - no other biases that might weaken inference. The silver standard included quasiexperimental tests with haphazard assignment of treatments (case-control or Before-After Control-Impact [BACI] designs).

\section{Methods}

\section{Methods of review}

We performed repeated searches of the peer-reviewed literature using Google Scholar, followed by a snowball method using the reference lists of $>100$ articles identified in the search. We searched with the following keywords: (control, damage, depredation, lethal, nonlethal, removal, or livestock) AND (predat* or carnivor*). For our quantitative summary of results, we included only peer-reviewed, published tests in our native languages (English and Slovenian) that (1) used experimental or quasi-experimental control with a design that allowed strong inference, (2) occurred on working livestock operations with free-ranging, native carnivores of North America or Europe, and (3) verified livestock losses. 
Table 1. Tests of interventions to prevent carnivore predation on livestock that met review criteria

\begin{tabular}{|c|c|c|c|}
\hline & \multicolumn{3}{|c|}{ Observed changes (if any) in livestock predation } \\
\hline & Decrease & No difference & Increase \\
\hline Lethal methods & $\begin{array}{l}\text { Quasi-experimental tests of culling gray } \\
\text { wolves (I) and culling, hunting, and } \\
\text { poaching Eurasian lynx (2) }\end{array}$ & $\begin{array}{l}\text { Quasi-experimental tests of hunting } \\
\text { black bears }\left(3^{*}\right), \text { hunting and culling } \\
\text { brown bears }(4) \text {, and culling and } \\
\text { hunting gray wolves (5) }\end{array}$ & $\begin{array}{l}\text { Quasi-experimental tests } \\
\text { of culling coyotes }(6) \text { and } \\
\text { hunting cougars }\left(7^{* *}\right)\end{array}$ \\
\hline Non-lethal methods & $\begin{array}{l}\text { Random assignment test of fladry on } \\
\text { gray wolves (8), random assignment test } \\
\text { of LGDs on gray wolves and coyotes ( } 9 \text { ), } \\
\text { quasi-experimental tests of LGDs and } \\
\text { night enclosures on gray wolves (I0), } \\
\text { and fladry on gray wolves (II) }\end{array}$ & $\begin{array}{l}\text { Random assignment test of fladry on } \\
\text { coyotes ( } 8) \text {, quasi-experimental tests } \\
\text { of diversionary feeding on brown } \\
\text { bears ( } 12 \text { ) }\end{array}$ & \\
\hline \multicolumn{4}{|c|}{ 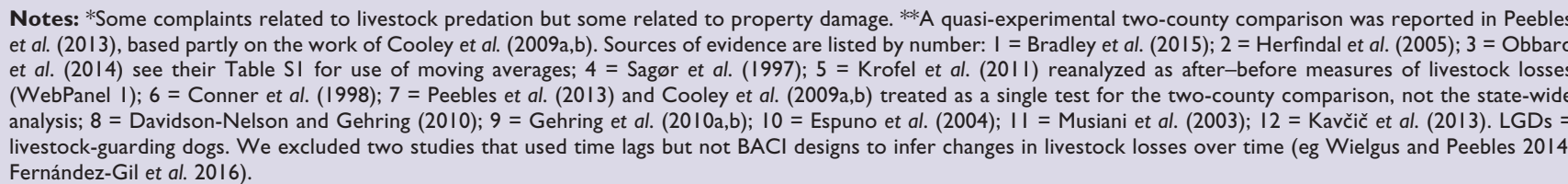 } \\
\hline
\end{tabular}

Regarding criterion (1), we explicitly describe the reasons any test was deemed unreliable based on selection, treatment, measurement, or reporting biases in WebPanel 1. We excluded analyses that were purely correlational, those based only on unverified estimates of livestock loss, and analyses in which $n \leq 4$ subjects (farms or livestock herds) completed the test. Several studies we mention in the footnote to Table 1 came close to the silver standard by calculating time lags in livestock loss following treatments but we omitted them because they failed to estimate change in livestock loss (after-before). We believe several of these might qualify if the data were reanalyzed.

Regarding criterion (2), we defined a working livestock operation as one in which livestock, land, and predators were managed in ways characteristic of a private livestock producer. That criterion excluded tests with captive predators (Jaeger 2004). We did not review qualifying tests from continents other than North America and Europe for two reasons. First, we excluded Australia because dingoes and red foxes are non-native species and their predation on livestock today may have been shaped by domestication and captivity, respectively, as a result of human-associated artificial selection for traits in these canids. Second, by excluding other continents, we avoided biased representation of tests published in languages that we (the authors) could not understand well enough to evaluate the research design. As WebPanel 1 and our descriptions below reveal, careful reading is necessary to understand research design.

Regarding criterion (3), we excluded studies measuring self-reported livestock losses or perceptions of effectiveness from Table 1. Although livestock owners' perceptions of interventions are important for the adoption of effective techniques, the functional effectiveness of candidate solutions should be established first. This exclusion reduced the number of allegedly effective non-lethal methods in particular.

\section{Methods of analysis}

Our quantitative summary was limited to counting tests in various categories. We did not attempt to perform a quantitative meta-analysis of effects, because there is no standard for consistent application of treatments and because the variety of methods used even within one category (eg different types of traps, or breeds of livestock-guarding dogs [LGDs]) would introduce uncontrollable variation. Furthermore, tests using the silver standard offer weaker inference than those using the gold standard but to an unknown degree.

We use the terms "culling" to refer to any variety of killing of wild predators by agents of the government and "hunting" to refer to regulated killing by private citizens.

\section{Geographic and taxonomic distribution}

The geographic distribution of tests in Europe and North America has been patchy, and the taxonomic distribution has concentrated on canids $(n=7)$, ursids $(n=3)$, and felids $(n=2)$ (Figure 1). The few tests involving wild felids and ursids do not suggest marked differences between taxonomic groups, as detailed below.

\section{Results}

\section{Flawed tests}

The earliest scientific studies had design flaws and a total of 12 tests (one published as recently as 2008) were excluded despite otherwise meeting our criteria (WebPanel 1); the earliest test with reliable inference was published in 1997 (Sagør et al. 1997). Our review of flawed tests revealed two important patterns. First, early investigations with design flaws have been cited 
uncritically, even after flaws were identified in peerreviewed, published articles (eg Mitchell et al. 2004). Second, seven tests of lethal methods and four (or five if one counts sterilization) tests of non-lethal methods had design flaws. All flawed tests were conducted in North America.

\section{Lethal methods}

Reliable inference was detected in only 7 tests of lethal methods that met the silver standard (those with quasi-experimental designs); tests of lethal methods that might have qualified for the gold standard were flawed (WebPanel 1). Of those 7 tests, only two were shown to reduce livestock losses from predation; in the remaining five, predation on livestock was unaffected in three tests and increased in two tests.

Using a quasi-experimental design to compare Eurasian lynx (Lynx lynx) predation on sheep across sites varying in the number of lynx killed over a 6-year period, Herfindal et al. (2005) reported that a lethal method (killing by various means) prevented sheep losses but only to a minor degree; prevention differed by site and its duration was short term. The test indicated that for every male and female lynx that were killed, 13 lambs and 2 lambs were saved, respectively. Because the range of each lynx encompassed multiple sheep flocks, the benefits to individual livestock owners averaged $<1$ lamb saved per lynx killed and were deemed to be "of little practical benefit" (Herfindal et al. 2005). Given that individual lynx differed substantially in their tendencies to prey on sheep, benefits were also geographically variable (Herfindal et al. 2005).

In three separate investigations of lethal control measures applied to bears, predation on livestock was unaffected or increased. For example, culling Norwegian brown bears (Ursus arctos) did not reduce predation on sheep (Sagør et al. 1997). Likewise, results from a study of American black bears (Ursus americanus) across Ontario, Canada, suggested that neither the number of black bears killed by hunters using various methods, nor bear population size, predicted future bear-related damage; rather, bear food availability was the best predictor (Obbard et al. 2014). A similar study in Wisconsin (Treves et al. 2010) did not include sufficient numbers of livestock losses among the incidents involving black bears for us to include in Table 1 but the results for agricultural damages of all sorts were similar when the data were reanalyzed as a BACI design.

Most quasi-experimental tests of lethal methods showed no effects or counterproductive effects on livestock loss. Slovenia's nationwide culling of 51 wolves, averaging 4.6 wolves or $\sim 25 \%$ of the population annually, was distributed among local management units proportional to the current wolf densities. In an 11-year study in Slovenia, Krofel et al. (2011) detected no effect of wolf culling on subsequent livestock losses, even when

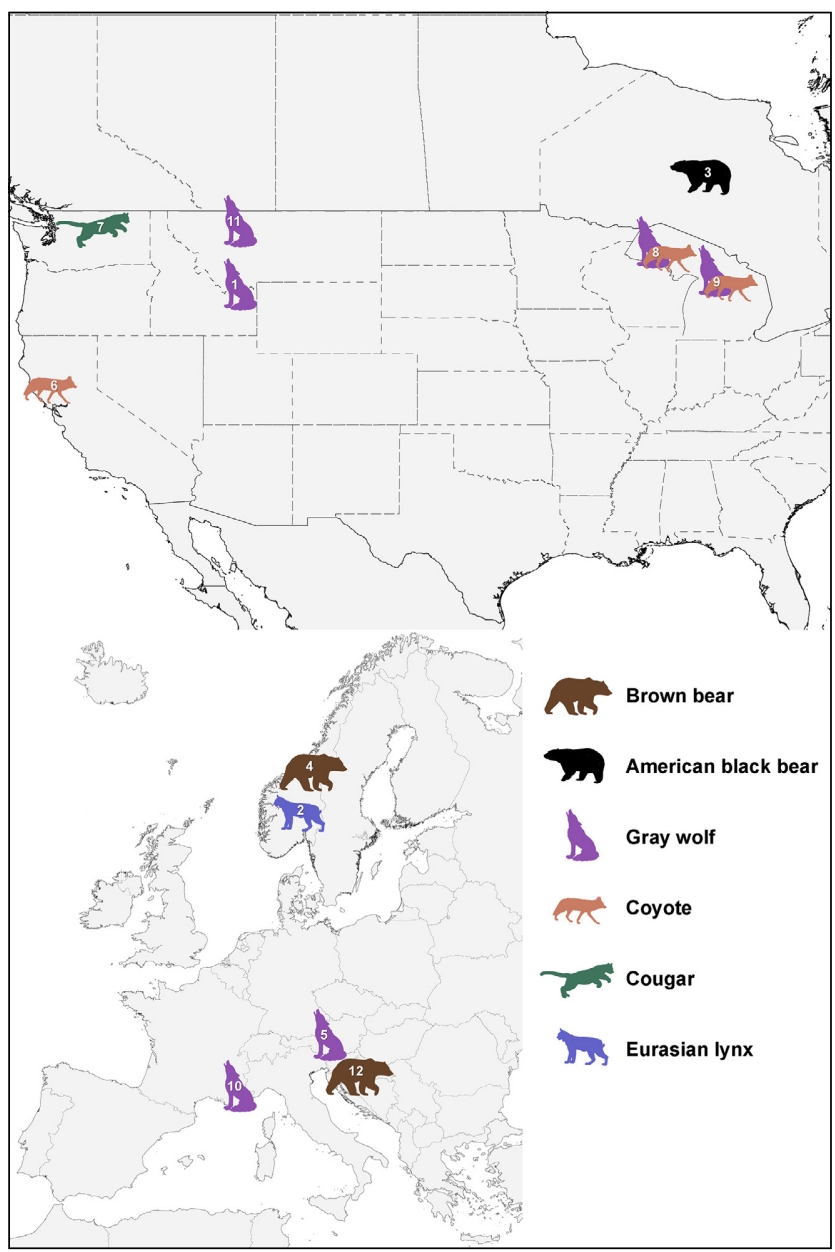

Figure 1. The geographic distribution of tests of lethal and non-lethal methods providing reliable inference about functional effectiveness in preventing carnivore predation on livestock from North American and European livestock farms. Numbers correspond to those in Table 1.

only the years with the most extreme killing rates were compared. The data for this test were reanalyzed in a BACI design to meet the silver standard (WebPanel 1). In 1998, researchers at the University of California's Hopland Research and Extension Center (HREC) investigated preventive effects of coyote killing (Conner et al. 1998) conducted using various methods (Figure 2). Conner et al. (1998) performed numerous analyses on the same data to test the effect of routine, non-selective coyote killing in preventing sheep predation. We focused only on those analyses that employed BACI designs (comparing lamb losses across consecutive seasons and those with time lags) and these reported counterproductive effects of killing more coyotes (Table 1).

Each of the quasi-experimental tests of lethal methods (Table 1) included unmeasured or uncontrolled variables, which may confound analyses and thereby weaken inference (see below for wolf culling and also WebPanel 1). However, one correlational study we would have excluded (Peebles et al. 2013) achieved silver standard when we 


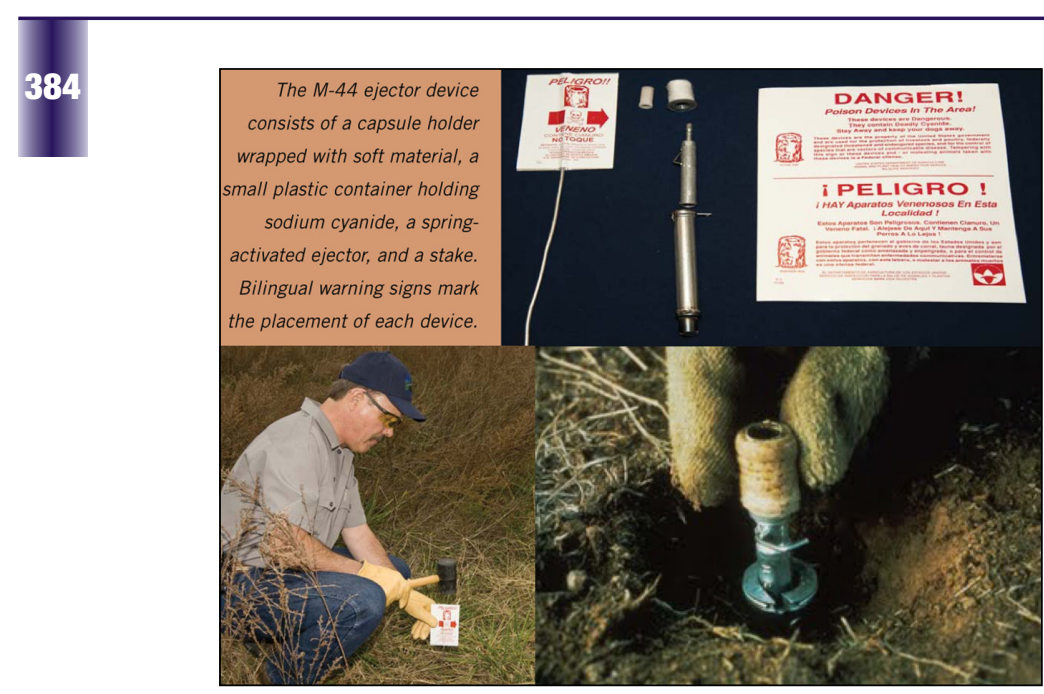

Figure 2. M-44 explosive poison (sodium cyanide) delivery device for killing wildlife (Factsheet May 2010, US Department of Agriculture Wildlife Services; http://1.usa.gov/28Iv69N).

considered it in combination with another study to qualify as a BACI design. Cooley et al.'s (2009 a,b) study of cougars (Puma concolor) strengthened the inference in Peebles et al. (2013) when looking only at the twocounty comparison in the latter paper. Specifically, Cooley et al. (2009 a,b) documented that hunting cougars led to demographic changes in a heavily hunted county and not in another county with much lower rates of cougar hunting (also see White et al. 2011). Later, Peebles et al. (2013) showed that livestock losses rose annually in correlation with the number of cougars taken by hunters but only in the county that experienced changes in cougar demography. We therefore judged that the two studies together provided the causal mechanism and the BACI design needed to identify it as a silver standard test in Table 1.

Potential confounding variables in two wolf culling studies illustrate how weak inferences from tests using the silver standard impede scientific consensus. Two teams (Wielgus and Peebles 2014; Bradley et al. 2015) came to opposite conclusions when analyzing the same data from the northern Rocky Mountain (NRM) wolf population. Although Wielgus and Peebles (2014) found that killing more wolves was followed by more livestock losses during the following year, it did not adequately account for the time series underlying livestock exposure and lethal interventions. We therefore excluded it from Table 1, pending reanalysis. The time series is critical to BACI designs in the silver standard. Namely, as the wolf population increased in size, it also spread geographically, thereby exposing more livestock to wolf predation. Because wolf killing increased over time as recolonizing wolves left strictly protected areas and as policy changes introduced more and more wolf-killing (Bradley and Pletscher 2005; Bradley et al. 2008, 2015), one would therefore expect the predictors (wolf killing, livestock exposed, and wolf distribution) to rise over time. This would create a positive correlation with the observed rise in livestock losses over time. Statistical control for encounters between wolves and livestock would require a measure of geographic spread of wolves, not just wolf and livestock abundance regionally (Wielgus and Peebles 2014). In contrast, Bradley et al. (2015) incorporated spatial information in their BACI design but limited their investigation in a critical way: restricting the spatial extent to pack territories.

Bradley et al. (2015) reported a reduction in livestock losses subsequent to culling within a wolf pack territory. The reductions were significant after an entire pack was killed, but insignificant when a few wolves were removed; when wolves were neither killed nor removed, no reduction in livestock losses was observed. The analysis was restricted to the affected wolf pack territory, despite the researchers' own work documenting how partial removal of wolves could scatter survivors beyond their original pack range or prompt take-over by a neighboring wolf pack (Bradley 2004; Bradley et al. 2008). The analysis should have examined neighboring areas and beyond, including ripple effects, whereby livestock losses recurred up to $16 \mathrm{~km}$ from sites of wolf culling (Treves et al. 2013). We recommend use of the gold standard for scientific inference to resolve the NRM wolf culling controversy. In sum, we find only weak inference for lethal methods and unconvincing evidence of preventive effects (Table 1).

\section{Non-lethal methods}

Non-lethal methods have long been examined but fewer of these studies met our criteria (five tests on six species; Table 1), because the measures of effect often came from livestock owners' perceptions rather than field verification. Of these five tests, four showed preventive effects; one test found preventive effects for wolves but not coyotes and one showed no effect. The latter - a BACI comparison in Slovenia that provided brown bears with livestock carcasses to deter or distract them from attacking sheep - revealed no change in livestock predation regionally (Kavčič et al. 2013). A large-scale, long-term study in France evaluated the effectiveness of 0-8 LGDs per pasture, and of mobile electric fences to confine sheep at night, against predation by wolves (Espuno et al. 2004). We include their study for the secondary analysis that tested sheep herds and pastures in relation to changes in the number of LGDs over time, not for their primary correlational model, which did not meet our criteria. From that secondary quasi-experimental test, Espuno et al. (2004) inferred that a combination of at least five LGDs and night enclosures (but neither in isolation) would prevent virtually all wolf predation on sheep (Figure $3 \mathrm{a}$ and b). In addition, two tests of non-lethal methods met the gold standard and showed preventive effects. One conducted on LGDs reported no livestock predation for control or treatment groups but detected an effect 
of preventing carnivore incursions into fenced pastures (Gehring et al. 2010a, 2010b). We considered prevention of carnivore incursions into livestock pastures to be a relevant measure of effect because incursions are an essential precursor to predation on livestock. Likewise, the technique known as fladry (in which flagging is mounted on fences or ropes as a visual deterrent to predators; Figure 4) also demonstrated preventive effects, in the best random-assignment test that we found (Davidson-Nelson and Gehring 2010). A similar test of fladry used a BACI design (Musiani et al. 2003). Fladry was found to be effective against wolves but not coyotes or black bears in the former test and in another random-assignment experiment that we excluded because it did not involve livestock (Shivik et al. 2003).

\section{Peer review}

Rigorous peer review is a component of the gold standard for scientific inference, but we could not assess the rigor of review in the published tests. Three journals published 10 of the 12 (83\%) articles with flawed designs (WebPanel 1), and only four of 12 (33\%) tests that were reliable (Table 1 ). The same society publishes two of the journals, one of which also published a strong critique of several of the flawed tests (Mitchell et al. 2004). Yet the three journals continued to publish articles citing the flawed tests as evidence without citing Mitchell et al. (2004). Indeed, the latter paper appears to have been cited only once in any of those three journals (http://bit.ly/28Joqto, accessed 22 Jan 2016; Web of Science and Science Reports indicated no citations in these journals).

\section{Conclusions}

\section{Effectiveness}

Tests of effectiveness of interventions to prevent carnivore predation on livestock were consistent across regions. Among 12 North American and European tests that met "gold" or "silver" standards for reliable inference, we found a greater proportion of non-lethal methods were effective in preventing carnivore predation on livestock than lethal methods ( $80 \%$ versus $29 \%$ ). Quasi-experimental tests of culling and hunting revealed positive, negative, and no effects (Table 1). None of the tests of lethal methods met the gold standard. Indeed, many combined several different methods of killing predators, including unregulated killing that would introduce uncontrolled variables. Culling and hunting appear risky for livestock owners because effects were slight or uncertain and five of seven tests produced no effect or a counterproductive effect (Table 1). This conclusion stands even without the inclusion of four studies that found counterproductive effects of killing wolves, bears, or cougars (Treves et al. 2010;
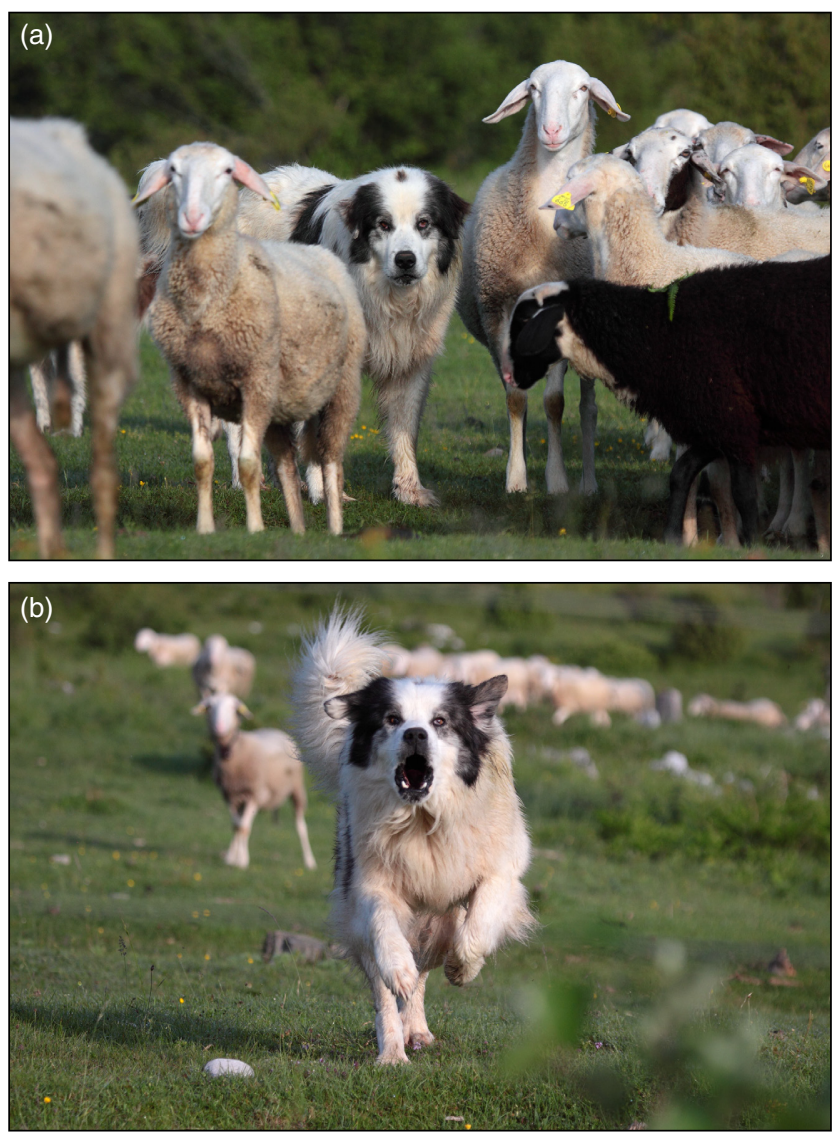

Figure 3. Livestock-guarding $\operatorname{dog}($ a) protecting sheep and (b) charging the approaching photographer.

Peebles et al. 2013; Wielgus and Peebles 2014; FernándezGil et al. 2016). The non-lethal methods that have been tested (LGD, fladry, night enclosures) were not associated with similar negative results.

Two studies - one relying on LGDs (Gehring et al. 2010 $a, b)$ and the other on fladry (Davidson-Nelson and Gehring 2010) - provide both strong inference and evidence of effectiveness in preventing predation on livestock. Although fladry may be limited to deterring wolves, LGDs have a long history and detailed technical information on appropriate breeds, husbandry, and deployment.

Our findings for selected sites in North America and Europe are consistent with tests conducted for Asiatic black bears (Ursus thibetanus) in Japan (Huygens et al. 2004), cougars in Mexico (Zarco-González and MonroyVilchis 2014), and canids and felids in South Africa (McManus et al. 2015). Using a pseudo-control, casecontrol design similar to BACI, the latter team found livestock losses and related costs declined for two consecutive years after implementing non-lethal methods (LGDs, alpacas [Vicugna pacos], and livestock protective steel collars) as compared with lethal methods (various kill-traps and shooting) in the first year of their study on the same livestock farms. Although the data on livestock losses were self-reported by livestock owners, the research- 


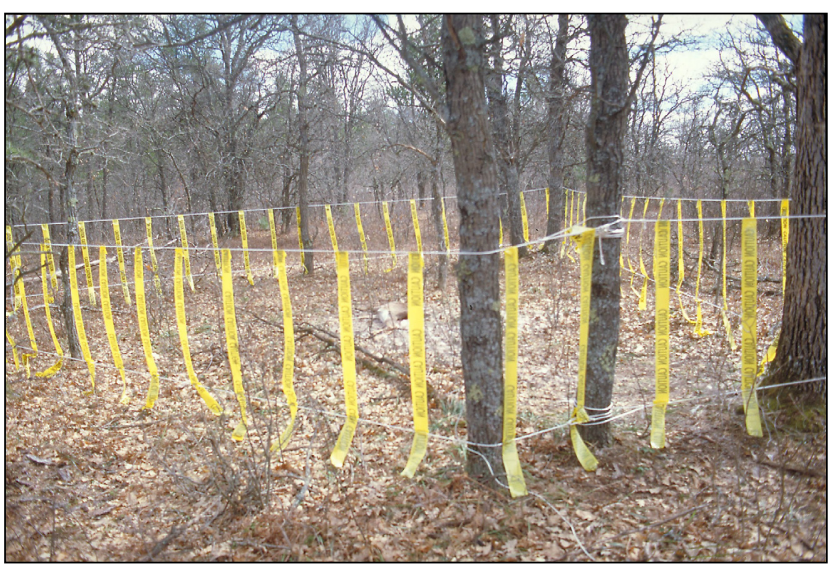

Figure 4. An experimental plot containing a road-killed deer carcass surrounded by a treatment of fladry - a flagging method used to deter wolves (Shivik et al. 2003).

ers trained the owners in verification techniques and issued field kits to improve verification (McManus et al. 2015).

\section{Strength of inference}

We found few random-assignment experiments 50 years after its importance for strong inference was first explained (Platt 1964). Of the tests that met our inclusion criteria (Table 1), 83\% were quasi-experimental tests using BACI comparisons. We considered that only two tests $(17 \%)$ both allowed reliable inference and approached the gold standard for experimental design. Other studies were excluded from our quantitative summary because of small sample sizes or unreliable inference (WebPanel 1). The gap between recommended experimental designs (Platt 1964; Hairston 1989) may partly reflect the difficulty of randomizing treatments around working livestock operations. However, the above-mentioned examples of gold standard tests of non-lethal methods emphasize the importance of developing more robust experimental designs for the future.

We recommend an independent scientific panel of experts be convened to conduct a large-scale experiment on predator control, as was done in the UK for badger culling (Vial and Donnelly 2012). Indeed, we suggest that this experiment be subject to an even higher "platinum standard", which would include "double blinds", where those measuring effects are unaware of the treatment and where analysts compare results without knowing which data were from treatment or control groups (Mukherjee 2010).

\section{Law, ethics, and ecological side effects}

Sound policy should be consistent with law, scientific evidence, and ethical standards of society. The EU
Habitats Directive and various US federal policies and laws (including the Endangered Species Act) require the use of evidence and in some cases specify the best available science (Treves et al. 2015). When two or more interventions to control predators are lawful, we recommend that farmers, managers, policy makers, and courts first consider functional effectiveness (will the intervention prevent future threats to human interests?) and the strength of inference for that effect. If two candidate interventions perform equally by those criteria, then we recommend that two additional criteria be considered before implementing predator control: public acceptance (will the intervention be supported by both the complainants and the general public?) and ecological consequences (will the intervention deplete biodiversity or ecosystem services?). We recommend continuing education requirements for wildlife managers to keep up-to-date with the best available science. We also suggest that decision makers should suspend predator control programs that do not meet standards of strong inference about effectiveness, especially if those have legal, ethical, or ecological drawbacks. The burden of proof should rest heaviest on the interventions that have the most serious negative effects on biodiversity, people, and livestock.

Comparisons between non-lethal and lethal methods (such as culling and hunting) reveal how multiple criteria support the use of non-lethal methods. Livestockguarding dogs and fladry outperformed lethal methods in functional effectiveness and were superior in strength of inference (Table 1). Lethal methods have additional limitations for managing predators and face a legal burden of proof in North America and Europe because of public trust principles or explicit protections (Epstein and Darpö 2013; Treves et al. 2015). The Habitats Directive 92/43/EEC, for example, restricts lethal controls to situations with an "absence of a satisfactory alternative" (Article 16, 2). Furthermore, recent court decisions in the US have restricted the use of predator control in several situations (Treves et al. 2015; http:// bit.ly/28J2mkq). Ethical decisions should also consider the values of society at large and the intrinsic worth of all of the individual animals involved (Vucetich and Nelson 2014). For instance, two large-scale studies in the US suggested lower public acceptance of lethal methods than of non-lethal methods and that humaneness was important to the public (Reiter et al. 1999; Slagle et al. in press). Finally, the negative ecological effects of killing carnivores have recently been documented in many regions (Ripple et al. 2014; Krofel et al. 2015). In many ecosystems, both terrestrial and aquatic, predators appear to play a disproportionate role not only in preventing excessive herbivory, which may result in long-term depletion of vegetation and its associated biodiversity, but also in enhancing species diversity. Regardless of whether predators directly regulate the numerical abundance of their prey or indirectly keep the 
survivors fearful, human-induced mortality, translocation, or sterilization methods for predator control may alter predator ecology and ecosystem dynamics with far-reaching effects.

In conclusion, we believe the science of predator control lacks rigor generally - the resulting uncertainty about the functional effectiveness of killing predators should guide evidence-based policy to non-lethal methods until gold standard tests are completed.

\section{Acknowledgements}

Financial support for research was provided by the Fulbright Program to AT, the Slovenian Research Agency (grant number P4-0059) and the Pahernik Foundation to MK, the Carnegie Corporation of New York to the Global Change and Sustainability Research Institute, University of the Witwatersrand, the ABAX Foundation, and the National Lotteries Distribution Trust Fund (to JM). JV Lopez-Bao and G Chapron provided invaluable feedback.

\section{References}

Allen LR and Sparkes EC. 2001. The effect of dingo control on sheep and beef cattle in Queensland. J Appl Ecol 38: 76-87.

Biondi F. 2014. Paleoecology grand challenge. Front Ecol Evol; doi:10.3389/fevo.2014.00050.

Bradley EH. 2004. An evaluation of wolf-livestock conflicts and management in the northwestern United States (MS thesis). Missoula, MT: University of Montana.

Bradley EH and Pletscher DH. 2005. Assessing factors related to wolf depredation of cattle in fenced pastures in Montana and Idaho. Wildlife Soc B 33: 1256-65.

Bradley EH, Pletscher DH, Bangs EE, et al. 2008. Evaluating wolf translocation as a nonlethal method to reduce livestock conflicts in the northwestern United States. Conserv Biol 19: 1498-508.

Bradley EH, Robinson HS, Bangs EE, et al. 2015. Effects of wolf removal on livestock depredation recurrence and wolf recovery in Montana, Idaho, and Wyoming. J Wildlife Manage 79: $1337-46$

Chapron G, Kaczensky P, Linnell JDC, et al. 2014. Recovery of large carnivores in Europe's modern human-dominated landscapes. Science 346: 1517.

Conner MM, Jaeger MM, Weller TJ, et al. 1998. Effect of coyote removal on sheep depredation in northern California. J Wildlife Manage 62: 690-99.

Cooley HS, Wielgus RB, Koehler GM, et al. 2009a. Source populations in carnivore management: cougar demography and emigration in a lightly hunted population. Anim Conserv 12: $321-$ 28.

Cooley HS, Wielgus RB, Robinson HS, et al. 2009b. Does hunting regulate cougar populations? A test of the compensatory mortality hypothesis. Ecology 90: 2913-21.

Davidson-Nelson SJ and Gehring TM. 2010. Testing fladry as a nonlethal management tool for wolves and coyotes in Michigan. Human-Wildlife Interactions 4: 87-94.

Epstein Y and Darpö J. 2013. The wild has no words: environmental NGOs empowered to speak for protected species as Swedish courts apply EU and international environmental law. J European Environ Planning Law 10: 250-61.

Espuno N, Lequette B, Poulle ML, et al. 2004. Heterogeneous response to preventive sheep husbandry during wolf recolonization of the French Alps. Wildlife Soc B 32: 1195-208.
Estes JA, Terborgh J, Brashares JS, et al. 2011. Trophic downgrading of planet Earth. Science 333: 301-06.

Fernández-Gil A, Naves J, Ordiz A, et al. 2016. Conflict misleads large carnivore management and conservation: brown bears and wolves in Spain. PLoS ONE 11: e0151541.

Fischer J, Brosi B, Daily GC, et al. 2008. Should agricultural policies encourage land sparing or wildlife-friendly farming? Front Ecol Environ 6: 380-85.

Gehring TM, VerCauteren KC, and Cellar AC. 2010a. Good fences make good neighbors: implementation of electric fencing for establishing effective livestock protection dogs. HumanWildlife Interactions 4: 144-49.

Gehring TM, VerCauteren KC, Provost ML, et al. 2010b. Utility of livestock-protection dogs for deterring wildlife from cattle farms. Wildlife Res 37: 715-21.

Gould SJ. 1980. The promise of paleobiology as a nomothetic, evolutionary discipline. Paleobiology 6: 96-118.

Greentree C, Saunders G, McLeod L, et al. 2000. Lamb predation and fox control in south-eastern Australia. J Appl Ecol 37: 935-43.

Haber GC. 1996. Biological, conservation, and ethical implications of exploiting and controlling wolves. Conserv Biol 10: 1068-81.

Hairston NG. 1989. Ecological experiments: purpose, design and execution. Cambridge, UK: Cambridge University Press.

Herfindal I, Linnell JDC, Moa PF, et al. 2005. Does recreational hunting of lynx reduce depredation losses of domestic sheep? J Wildlife Manage 69: 1034-42.

Huygens OC, van Manen FT, Martorello DA, et al. 2004. Relationships between Asiatic black bear kills and depredation costs in Nagano Prefecture, Japan. Ursus 15: 197-202.

Jaeger MM. 2004. Selective targeting of alpha coyotes to stop sheep depredation. Sheep Goat Res J 19: 80-84.

Kavčič I, Adamič M, Kaczensky P, et al. 2013. Supplemental feeding with carrion is not reducing brown bear depredations on sheep in Slovenia. Ursus 24: 111-19.

Knowlton FF, Gese EM, and Jaeger MM. 1999. Coyote depredation control: an interface between biology and management. J Range Manage 52: 398-412.

Krofel M, Cerne R, and Jerina K. 2011. Effectiveness of wolf (Canis lupus) culling as a measure to reduce livestock depredations. Acta Silvae et Ligni 95: 11-22.

Krofel M, Treves A, Ripple WJ, et al. 2015. Hunted carnivores at outsized risk. Science 350: 518.

Linnell JDC, Aanes R, Swenson JE, et al. 1997. Translocation of carnivores as a method for managing problem animals: a review. Biodivers Conserv 6: 1245-57.

Mason JR, Shivik JA, and Fall MW. 2001. Chemical repellents and other aversive strategies in predation management. Endangered Species Update 18: 175-81.

McManus J, Dickman A, Gaynor D, et al. 2015. Dead or alive? Comparing costs and benefits of lethal and non-lethal humanwildlife conflict mitigation on livestock farms. Oryx 49: 687-95.

Mitchell BR, Jaeger MM, and Barrett RH. 2004. Coyote depredation management: current methods and research needs. Wildlife Soc B 32: 1209-18.

Mukherjee S. 2010. The emperor of all maladies: a biography of cancer. New York, NY: Scribner.

Musiani M, Mamo C, Boitani L, et al. 2003. Wolf depredation trends and the use of fladry barriers to protect livestock in western North America. Conserv Biol 17: 1538-47.

Newby F and Brown R. 1958. A new approach to predator management in Montana. Montana Wildlife 8: 22-27.

Obbard ME, Howe EJ, Wall LL, et al. 2014. Relationships among food availability, harvest, and human-bear conflict at landscape scales in Ontario, Canada. Ursus 25: 98-110.

Peebles K, Wielgus RB, Maletzke BT, et al. 2013. Effects of remedial sport hunting on cougar complaints and livestock depredations. PLoS ONE 8: e79713. 
Platt JR. 1964. Strong inference. Science 146: 347-53.

Prugh LR, Stoner CJ, Epps CW, et al. 2009. The rise of the mesopredator. BioScience 59: 779-91.

Reiter DK, Brunson MW, and Schmidt RH. 1999. Public attitudes toward wildlife damage management and policy. Wildlife Soc B 27: 746-58.

Ripple WJ, Estes JA, Beschta RL, et al. 2014. Status and ecological effects of the world's largest carnivores. Science 343; doi: $10.1126 /$ science. 1241484 .

Sagør JT, Swenson JE, and Roskaft E. 1997. Compatibility of brown bear Ursus arctos and free-ranging sheep in Norway. Biol Conserv 81: 91-95.

Shivik JA, Treves A, and Callahan M. 2003. Non-lethal techniques: primary and secondary repellents for managing predation. Conserv Biol 17: 1531-37.

Slagle KM, Bruskotter JT, Singh AS, et al. Attitudes toward predator control in the United States: 1995 and 2014. J Mammal. In press.

Treves A, Chapron G, López-Bao JV, et al. 2015. Predators and the public trust. Biol Rev; doi:10.1111/brv.12227.

Treves A, Jurewicz RL, Naughton-Treves L, et al. 2002. Wolf depredation on domestic animals: control and compensation in Wisconsin, 1976-2000. Wildlife Soc B 30: 231-41.

Treves A, Kapp KJ, and Macfarland DM. 2010. American black bear nuisance complaints and hunter take. Ursus 21 : $30-42$.

Treves A and Karanth KU. 2003. Human-carnivore conflict and perspectives on carnivore management worldwide. Conserv Biol 17: 1491-99.

Treves A and Naughton-Treves L. 2005. Evaluating lethal control in the management of human-wildlife conflict. In: Woodroffe R, Thirgood S, and Rabinowitz A (Eds). People and wildlife, conflict or coexistence? Cambridge, UK: Cambridge University Press.

Treves A, Vucetich JA, Rabenhorst M, et al. 2013. An evaluation of localized wolf control efforts to prevent subsequent livestock depredation in Michigan. Natural Resources Report No 201314: Little River Band of Ottawa Indians.
Treves A, Wallace RB, and White S. 2009. Participatory planning of interventions to mitigate human-wildlife conflicts. Conserv Biol 23: 1577-87.

Vial F and Donnelly C. 2012. Localized reactive badger culling increases risk of bovine tuberculosis in nearby cattle herds. Biol Lett 8: 50-53.

Vucetich J and Nelson MP. 2014. Wolf hunting and the ethics of predator control. Political science, comparative politics, political theory. Oxford, UK: Oxford Handbooks Online.

White KS, Koehler GM, Maletzke BT, et al. 2011. Differential prey use by male and female cougars in Washington. J Wildlife Manage 75: 1115-20.

Wielgus RB and Peebles K. 2014. Effects of wolf mortality on livestock depredations. PLoS ONE 9: e113505.

Wirsing AJ and Ripple WJ. 2010. A comparison of shark and wolf research reveals similar behavioral responses by prey. Front Ecol Environ 9: 335-41.

Woodroffe R and Redpath S. 2015. When the hunter becomes the hunted. Science 348: 1312-14.

Young SP and Dobyas HW. 1945. Coyote control by means of den hunting. Washington, DC: US Department of the Interior, Fish and Wildlife Service.

Zarco-González MM and Monroy-Vilchis O. 2014. Effectiveness of low-cost deterrents in decreasing livestock predation by felids: a case in central Mexico. Anim Conserv 17: 371-78.

\section{Supporting Information}

Additional, web-only material may be found in the online version of this article at http://onlinelibrary.wiley. com/doi/10.1002/fee.1312/suppinfo

\footnotetext{
${ }^{3}$ Research Department, Landmark Foundation, Riversdale, South Africa, and School of Animal, Plants and Environmental Sciences, University of Witwatersrand, Johannesburg, South Africa; ${ }^{\dagger}$ these authors contributed equally to this work
}
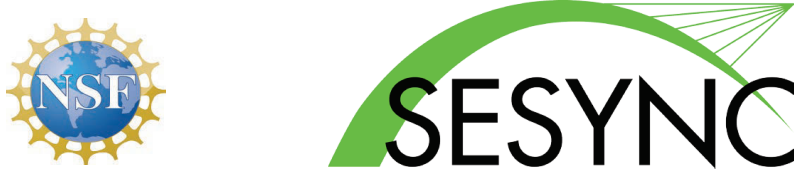

The National Socio-Environmental Synthesis Center Postdoctoral Fellowship Program

The National Socio-Environmental Synthesis Center (SESYNC), located in Annapolis, Maryland, invites applications from early career scholars ( $\leq 4$ years post $\mathrm{PhD}$ ) for 2-year postdoctoral fellowships that begin August 2017. Fellows will co-develop research projects with Collaborating Mentors using synthesis methods to address a problem arising from, or associated with, the relationship between humans and nature. Fellows will also participate in the Socio-Environmental Immersion Program, which includes a learning component that will steep participants in theory foundational to understanding socio-environmental systems. For more information, please visit: http://sesync.us/postdocim.

In collaboration with the Long-Term Ecological Research (LTER) network, SESYNC also invites applications that propose to use long term data sets, ongoing experiments, or modeling results from LTER sites. For more information about the SESYNC-LTER Postdoctoral Fellowship, please visit: http://sesync.us/postdoclter.

\section{Pre-screening applications due October 24, 2016, but are accepted on a rolling basis and should be submitted as soon as possible. Full applications are due December 5, 2016.}

